\title{
Health needs assessment in patients assisted by a pharmaceutical non-profit charitable organisation: a preliminary pharmacoepidemiological survey based on the analysis of drug dispensation within Italy's Banco Farmaceutico
}

\author{
Silvia Bini, ${ }^{1}$ Antonello E. Rigamonti, ${ }^{1}$ Francesco Fiorini, ${ }^{2}$ Pietro A. Bertazzi, ${ }^{1}$ Gian Francesco Fiorini, ${ }^{3}$ \\ Silvano G. Cella ${ }^{1}$ \\ ${ }^{1}$ Department of Clinical Sciences and Community Health, University of Milano, Italy; ${ }^{2}$ King's College London School of \\ Medicine, Guy's Campus, London, UK; ${ }^{3}$ Maggiore General Hospital, Crema, Italy
}

\begin{abstract}
We performed a health needs assessment of the vulnerable population cared for by the Banco Farmaceutico, an Italian nonprofit charitable organization that supplies medicines for many centers belonging to different charities. Drugs dispensed in the first half of 2014 by a representative sample of these centers were examined. An independently conducted telephone interview on our centers complemented this data. Adult males and migrants constituted the majority of the user population, and the most dispensed drugs were those for the respiratory system. Of all patients, $40 \%$ presented with a chronic problem and more than half needed polypharmacy. Users seek help spontaneously in $70 \%$ of the cases, with the centers being able to meet $80 \%$ of the existing demand. Patients that could not be managed were referred to local hospitals or collaborating doctors and reasons were explored. We believe our study to be a first attempt to characterise a growing population that is also increasingly represented in emergency departments and internal medicine wards. It is also an evaluation of the quality of data collected by charitable institutions, highlighting a significant need for improvement as they could be the only basis to monitor the health needs of this type of population.
\end{abstract}

\section{Introduction}

Understanding a given population's health status is crucial in order to improve the efficiency of available healthcare services. Optimizing interventions, cutting superfluous costs and targeting health needs is particularly important when adequate medical treat-

Correspondence: Silvano G. Cella, Department of Clinical Sciences and Community Health - Clinical Pharmacology, University of Milano, via Vanvitelli 32, 20129 Milano, Italy. Tel.: +39.02.503.17015.

E-mail: silvano.cella@unimi.it

Key words: Pharmacoepidemiology; poverty; health needs assessment; drug dispensation; charities.

Conflict of interest: the authors declare no potential conflict of interest.

Received for publication: 11 February 2015.

Revision received: 30 March 2015.

Accepted for publication: 20 April 2015.

This work is licensed under a Creative Commons Attribution NonCommercial 4.0 License (CC BY-NC 4.0).

CCopyright S. Bini et al., 2016

Licensee PAGEPress, Italy

Italian Journal of Medicine 2016; 10:111-118

doi:10.4081/itjm.2015.590 ment is more difficult to obtain, such as in a vulnerable population. ${ }^{1}$

Health needs assessment is a dynamic variable based on flexible and evolving indicators that can help to better tailor public health response. These indicators must be predictive of future needs, have good analytical accuracy and follow diagnostic and therapeutic innovations.

Mortality is often considered as the strongest epidemiological indicator ${ }^{2}$ but it describes only partially the health need of a population, as it focuses solely on conditions with an ominous prognosis. Moreover, it relies on death certificates that can often be inaccurate, without taking into account possible epidemiological biases. ${ }^{3}$

Access to treatment is another good indicator of general well-being but depends heavily on socio-economic factors, which also influence health itself. ${ }^{4}$ Therefore, drug prescription is becoming an internationally accepted indicator to evaluate a population's wellbeing. It is especially useful if a biunivocal correspondence exists between a given drug (or a group of drugs) and a certain disease, and when prescriptions are necessary rather than discretionary. ${ }^{5,6}$ The main limitation of this indicator is however the need to subjectively pair drugs to their associated diseases, based on their alleged rather than actual use. We have considered appropriate the use of this method of investigation since the data we have are complete regarding the drugs dispensed, but patients are not registered at 
their access to the centres and without their consent no information on their complaints and illnesses are stored and thus currently available.

Having taken this into account, we analysed drug dispensation to assess the health needs in the vulnerable population cared for by the Banco Farmaceutico (BF) - a charitable pharmaceutical non-profit organisation operating in Italy. ${ }^{7}$

\section{Materials and Methods}

\section{Population}

The population in this survey consists of a sample of Italian and foreign citizens receiving assistance by the BF. To do so, we selected 46 representative centers among those belonging to different charities who collaborate with the BF, based on the completeness of the data they supplied. In order to investigate geographical differences in drug dispensation, these charities were grouped into three macro-areas (Northern, Central, and Southern Italy). Considering the great variability in the quality of data provided by the charities as a whole, a secondary end-point of our work (not presented here) was the evaluation of each center, in order to improve data collection for future studies. The population is described according to gender, age distribution (three groups: $\leq 17,18-64$, and $\geq 65$ years old) and Italian or foreign citizenship.

To define the above characteristics of the study population, we only could rely on the percentages estimated by the employees of the centers, since our series mainly consisted of particular patients who, due to reasons of personal privacy (e.g., do not disclose their poverty or illegal status), rather than being registered often prefer to refuse our help. For this reason they were not asked about their nationality, type of accommodation and occupation. Therefore, it was not possible to associate the consumption of drugs with the individual characteristics of each patient and thus assessing the differences across the groups. We are well aware that this represents a bias in our study, but considering such a peculiar population, it was not possible to do otherwise.

\section{Data source}

The data in this cross-sectional study - collected in the period January-June 2014 - includes: identification code of the dispensing centre, anatomical-therapeuticchemical (ATC) code of the dispensed drugs, number of units dispensed, number of users and population characteristics as listed above.

Moreover, between September 1-15, 2014 we commissioned to DoxaPharma (an Italian research agency operating in the pharmaceutical and health sector) a computer aided telephone interview (CATI) on voluntaries of the centers. CATI was based on a specifically designed questionnaire lasting $10 \mathrm{~min}$ and focusing on 9 topics: i) mode of access of users to the dispensing centre; ii) percentage of patients with acute and chronic disease; iii) percentage of patients needing more than 1 drug; iv) most frequent diseases treated; v) untreated diseases and underlying reason; vi) drugs needed but unavailable in the previous 12 months; vii) percentage of requests met in the previous 12 months; viii) evaluation of compliance to treatment; ix) periods of greatest patient demand.

\section{Data analysis}

Drugs were grouped according to the taxonomic ATC classification and their quantities calculated using their defined daily dose (DDD), both methods recommended by the World Health Organization to measure drug utilisation. ${ }^{6}$ The ATC classification is a taxonomic method, widely established at international level. It is based on the classification of drugs according to the organs or systems on which they act and their chemical, pharmacological and therapeutic properties. The DDD, instead, is a technical unit of measure representing the daily maintenance dose in adults, relatively to the main therapeutic indication of the drug. It is therefore a standard unit and not the recommended dose for the individual patient, which may vary according to many other factors, such as age, genetic determinants, presence of co-morbidity, multiple drug treatments, etc. ${ }^{5,6}$ The amount of dermatological products, which lack a DDD, was calculated on the basis of units dispensed. We thus obtained a concise representation of the therapeutic needs of our users. All data are expressed as mean \pm standard deviation, or as percentage as appropriate.

\section{Results}

\section{Quality of centers}

A geographical gradient was observed in the dispensing centers selected for this analysis: 31 were located in the North of the Country, 10 in the Center and 5 in the South. We preliminarily assessed that they assisted a patients' sample representative of the entire population cared for by BF in terms of gender and age distribution and Italian to migrant ratio.

\section{Users population}

The study population was represented by all the Italian and foreign patients cared for by the centers selected for our analysis. A total of 116,373 subjects were studied. We observed a decrease from North to South in the number of users receiving assistance from the $\mathrm{BF}$ (Table 1), with $53.8 \%$ in the North, $37.9 \%$ in the Center, 
and only $8.3 \%$ in the South. Interestingly though, the average number of patients assisted per center is markedly higher in Central Italy (4415 $\pm 2016.3 /$ center), with no significant differences between North (2020.1 \pm 664.7$)$ and South $(1920 \pm 1035.1)$.

In all three geographical areas, the majority of patients utilising this service were adults aged 18-65, with more immigrants overall than those of Italian extraction - though this difference is less accentuated in the Northern region (Table 2). Male and female users constitute respectively $54.3 \%$ and $45.7 \%$ of the total population but greater disproportion exists within each macro-area, with more male than female patients both in the North and South while the opposite is true in the Center of the Country (Table 2).

The principal mode of access to the centers is spontaneous contact $(70 \%)$, while fewer are referred by social services $(16 \%)$, accident and emergency $(10 \%)$ or general practitioners $(4 \%)$.

Furthermore, while the majority of patients pre- sented with an acute illness (60\%), still a substantial proportion (40\%) complained of a chronic disease, and most patients (56\%) required polypharmacy.

\section{Drugs dispensed}

Within the time frame of the study, the centers distributed more than 875,000 DDD regardless the type of drug, with the Northern region dispensing by far the greatest amount of DDD both in total $(735,576$ DDD) and per center (Table 3).

Table 4 shows the ATC classes of drugs that were most prescribed in our BF centers, calculated as DDD/1000 patients/day. The most frequently dispensed drugs were overall those for the respiratory system, followed by gastrointestinal (GI) and metabolic medicines, cardiovascular, systemic antimicrobials and musculoskeletal ones.

However, considerable geographical differences were noticed. While this trend is mirrored well in the North, in Central Italy the most issued drugs were car-

Table 1. Quantification of the population assisted by the centers.

\begin{tabular}{lccc}
\hline & Number of patients & $\begin{array}{c}\text { Number of patients per center } \\
(\text { mean } \pm \text { standard deviation) }\end{array}$ & \multicolumn{1}{c}{ Geographical distribution (\%) } \\
\hline North & 62,624 & $2020.1 \pm 664.7$ & 53.8 \\
\hline Center & 44,149 & $4415 \pm 2016.3$ & 37.9 \\
\hline South & 9600 & $1920 \pm 1035.1$ & 8.3 \\
\hline Total & 116,373 & $2529.8 \pm 641.1$ & 100 \\
\hline
\end{tabular}

Table 2. Characteristics of the surveyed population. Data are expressed as percent.

\begin{tabular}{lccccccc}
\hline & $\begin{array}{c}\text { Minors } \\
(<\mathbf{1 7} \text { years })\end{array}$ & $\begin{array}{c}\text { Adults } \\
(\mathbf{1 8 - 6 5} \text { years })\end{array}$ & $\begin{array}{c}\text { Elderly } \\
(>\mathbf{6 5} \text { years })\end{array}$ & Italian & Foreign & Male & Female \\
\hline North & 18.2 & 73.3 & 8.5 & 46.2 & 53.8 & 65.6 & 34.4 \\
\hline Center & 26.6 & 41.9 & 31.5 & 30.0 & 70.0 & 36.8 & 63.2 \\
\hline South & 25.6 & 48.1 & 26.3 & 42.8 & 57.2 & 60.9 & 39.1 \\
\hline Total & 22.0 & 59.3 & 18.7 & 39.8 & 60.2 & 54.3 & 45.7 \\
\hline
\end{tabular}

Table 3. Daily defined dose dispensed by the centers between January-June 2014, independent of anatomical-therapeutic-chemical code category.

\begin{tabular}{lcc}
\hline & Dispensed DDD & $\begin{array}{c}\text { Dispensed DDD per center } \\
\text { (mean } \pm \text { standard deviation) }\end{array}$ \\
\hline Total & $875,036.5$ & $19,022.5 \pm 5017.1$ \\
\hline North & $735,576.0$ & $23,728.3 \pm 7175.0$ \\
\hline Center & $91,091.4$ & $9109.1 \pm 4175.4$ \\
\hline South & $48,369.2$ & $9673.8 \pm 5254.9$
\end{tabular}

DDD, defined daily dose. 
diovascular and not respiratory ones, whereas in the South musculoskeletal medicines were the most prescribed (Table 4).

Table 5 summarises which drugs were most frequently prescribed within each ATC class. Among respiratory medicines, we found that over-the-counter compounds for pharyngeal diseases and nasal decongestants were the most requested, with systemic and topical relievers of airway obstruction also well-represented. Gastro-oesophageal reflux disease (GORD) and diabetic control medicines were the principal GI and metabolic compounds prescribed. Statins, ACE inhibitors and $\mathrm{Ca}^{2+}$ blockers led the cardiovascular class, whereas $\beta$-lactams and quinolones the antimicrobial one.

\section{Presenting illness}

CATI data confirmed almost entirely the trend already set by the most frequently dispensed ATC groups: our patients are predominantly affected by respiratory illnesses (mainly airway infections), followed by gastrointestinal (GORD and peptic ulcer) and cardiovascular (mainly hypertension) diseases (Figure 1).

Table 4. Principal anatomical-therapeutic-chemical code (ATC) categories of pharmaceutical products prescribed by the centers between January-July 2014. ATC classes that were rarely or never prescribed are not shown.

\begin{tabular}{|c|c|c|c|c|}
\hline \multirow[b]{2}{*}{ ATC } & \multicolumn{4}{|c|}{ DDD/1000 patients/day } \\
\hline & Total & North & Center & South \\
\hline A - Alimentary tract and metabolism & 6.1 & 9.3 & 1.6 & 5.8 \\
\hline B - Blood and blood forming organs & 0.4 & 0.3 & 0.6 & 0.0 \\
\hline C - Cardiovascular system & 6.0 & 8.2 & 4.0 & 1.1 \\
\hline D - Dermatologicals & 0.9 & 1.6 & 0.1 & 0.2 \\
\hline G - Genito-urinary system and sex hormones & 0.6 & 0.7 & 0.1 & 0.1 \\
\hline H - Systemic hormones (excluding sex hormones) & 0.3 & 0.2 & 0.4 & 0.1 \\
\hline $\mathrm{J}$ - Anti-infectives for systemic use & 4.4 & 6.5 & 1.2 & 5.9 \\
\hline L - Antineoplastic and immunomodulators & 0.1 & 0.1 & 0.1 & 0.0 \\
\hline M - Musculo-skeletal system & 2.3 & 2.9 & 0.3 & 7.7 \\
\hline $\mathrm{N}$ - Nervous system & 1.0 & 1.3 & 0.4 & 0.7 \\
\hline R - Respiratory system & 20.5 & 35.5 & 2.3 & 6.6 \\
\hline S - Sensory organs & 0.1 & 0.1 & 0.1 & 0.0 \\
\hline
\end{tabular}

DDD, defined daily dose; ATC, anatomical-therapeutic-chemical code.

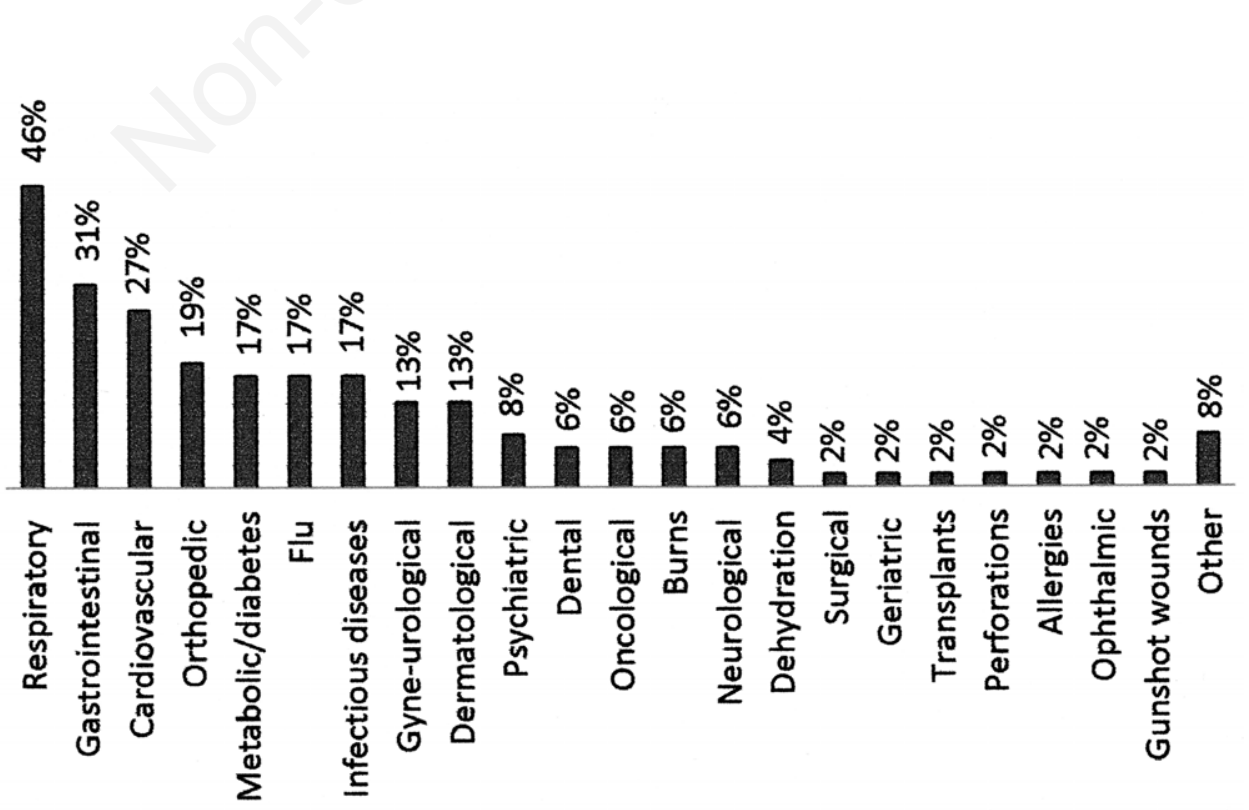

Figure 1. Most frequently encountered illnesses in the dispensing centers. Data are expressed as percentages. 
Moreover, the vast majority (64\%) of centers interviewed acknowledged their inability to deal with certain illnesses, particularly the psychiatric (24\%), oncologic (18\%) and genitourinary (15\%) ones (Figure 2). In these cases, lack of treatment was chiefly due to lack of specific competences $(70 \%)$, followed by unavailability of appropriate drugs, sub-specialisation of the centre in the treatment of only certain ill- nesses and, more in general, organisation problems (Figure 3). However, patients who cannot be treated are not rejected: they can be referred to the nearest emergency department (62\%), general practitioners volunteering in conjunction with the centers $(21 \%)$, or nearby specialist centres $(8 \%)$. Only in a small percentage of cases $(6 \%)$ no intervention was possible. In addition to this, most of the centers $(75 \%)$ re-eval-

Table 5. Main pharmaceutical agents prescribed by the centers within each anatomical-therapeutic-chemical code class used.

\begin{tabular}{|c|c|}
\hline ATC category & Pharmaceutical agents most commonly prescribed by selected BF centres \\
\hline A - Alimentary tract and metabolism & $\begin{array}{l}\text { Antiulcer (peptic) and GORD (rabeprazole sodium); hypoglycemic agents (gliclazide); } \\
\text { vitamins A and D (colecalciferol) }\end{array}$ \\
\hline B - Blood and blood forming organs & Antithrombotics (enoxaparin sodium, warfarin sodium, ticlopidine hydrochloride) \\
\hline C - Cardiovascular system & $\begin{array}{l}\text { Cholesterol-lowering (atorvastatin calcium); ACE inhibitors (enalapril maleate) } \\
\text { hydrochlorothiazide); } \mathrm{Ca}^{2+} \text { blockers dihydropyridines (manidipine hydrochloride) }\end{array}$ \\
\hline D - Dermatologicals & $\begin{array}{l}\text { Emollients (salicylic acid/zinc oxide); antiseptics and disinfectants (hydrogen peroxide 30\%); } \\
\text { topical antibiotics (gentamicine sulphate) }\end{array}$ \\
\hline G - Genito-urinary system and sex hormones & Benign prostatic hyperplasia (alfuzosin hydrochloride, tamsulosin hydrochloride) \\
\hline $\begin{array}{l}\text { H - Systemic hormonal preparations, } \\
\text { excluding sex hormones }\end{array}$ & $\begin{array}{l}\text { Systemic corticosteroids (prednisone, methylprednisolone); thyroid compounds } \\
\text { (levothyroxine sodium) }\end{array}$ \\
\hline J - Anti-infectives for systemic use & $\begin{array}{l}\text { B-lactam penicillins (amoxicillin clavulanate potassium, amoxicillin); quinolones (levofloxacin } \\
\text { hemihydrate) }\end{array}$ \\
\hline L - Antineoplastic and immunomodulators & $\begin{array}{l}\text { Hormonal antagonists (bicalutamide); hormonal agents (megestrol acetate); immunosuppressants } \\
\text { (azathioprine) }\end{array}$ \\
\hline M - Musculo-skeletal system & NSAIDs (ibuprofen, ketoprofen lysine salt); bone and mineral (ibandronate sodium monohydrate) \\
\hline N - Nervous system & $\begin{array}{l}\text { Opioids (tramadol hydrochloride); other analgesics and antipyretics (paracetamol); } \\
\text { Antiepileptics (topiramate) }\end{array}$ \\
\hline R - Respiratory system & $\begin{array}{l}\text { Pharingeal preparations (diclorofenilcarbinol/amilmetacresol/sodium ascorbate/ascorbic acid, } \\
\text { diclorofenilcarbinol/amilmetacresol); nasal decongestants (xylometazoline hydrochloride); } \\
\text { systemic compounds for airway obstruction (montelukast sodium); nebulised compounds for } \\
\text { airway obstruction (flunisolide); systemic antihistamines (cetirizine dihydrochloride) }\end{array}$ \\
\hline S - Sensory organs & $\begin{array}{l}\text { Antiglaucoma and miotics (acetazolamide, timolol maleate, dorzolamide hydrochloride/timolol } \\
\text { maleate) }\end{array}$ \\
\hline
\end{tabular}

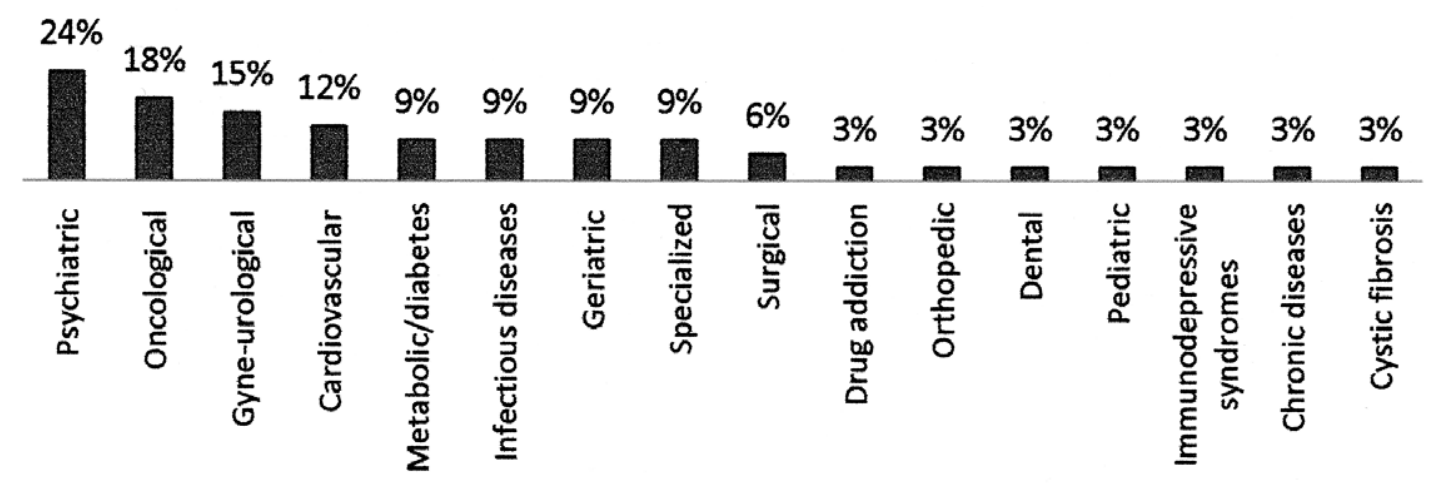

Figure 2. Main pathologies not treated by the dispensing centers. Data are expressed as percentages. 
uate the patients who accept to be monitored after treatment, either with periodic visits (54\%), blood and/or other tests $(11 \%)$, or invitation to the outpatient clinic for follow-up (11\%). It is also worth mentioning that $80 \%$ of total requests were met by BF centers in this time period. Lastly, CATI data indicates that the activity of the centers peaks in winter months and has its minimum in summer.

\section{Discussion}

Unlike the Italian general population, in which cardiovascular medicines are the most prescribed in the same observation period, ${ }^{8}$ the vulnerable population cared for by the charities entering the study appears to be affected above all by respiratory tract diseases.

Low socio-economic conditions-based on level of education, occupation, type of accommodation and space available per occupant-have been shown in several studies to be related to the incidence, morbidity and mortality of respiratory diseases. ${ }^{9-12}$ This could be due to a number of factors, from increased exposure to pollutants to dietary deficiencies and infections. ${ }^{13,14}$ Unhealthy lifestyles such as cigarette smoking and alcohol consumption are also more frequent in similar populations ${ }^{15-19}$ and are known contributing elements to these pathologies. Children are acutely affected by these environments, as migrant families in Italy have been found to seek emergency medical assistance for their offspring mainly for respiratory ailments. ${ }^{20}$ It is also known that low socio-economic conditions early in life entail an increased risk of chronic respiratory diseases in adulthood. ${ }^{21}$ Furthermore, we noted among the drugs dispensed for respiratory disorders a significant request for oropharyngeal disinfectants, nasal decongestants, and paediatric antipyretics. The financial difficulties that characterise the majority of our patient group are a substantial obstacle to the purchase of these over-thecounter products, which are not covered by the national Italian healthcare system (SSN). This is consistent with the greater demand that is dealt with by our centers during winter-time compared to summer months.

Interestingly, a bias in the dispensation of cardiovascular drugs could reside in the fact that our population is relatively young and these diseases are more frequently encountered in the elderly. This is also supported by the observation that cardiovascular drugs occupy the first position in the centers located in Central Italy, where there is a higher proportion of elderly patients seeking medical assistance.

The use of anti-ulcer drugs is also known to be higher amongst low-income people and immigrants, ${ }^{22}$ as is the case in our study population: the epidemiological explanation for this could be that the incidence of helicobacter pylori infections has been shown to be inversely related to socio-economic level, education, occupation and, more in general, life conditions. Once again children are particularly susceptible to these and are often carriers. ${ }^{23}$

In addition to this, CATI data highlight a high percentage of hypertensive patients in our population, which can be partly explained by unhealthy lifestyles; ${ }^{24-27}$ for example obesity has been shown to have a higher prevalence in immigrants than in residents. ${ }^{28}$ This is especially important as higher educa-

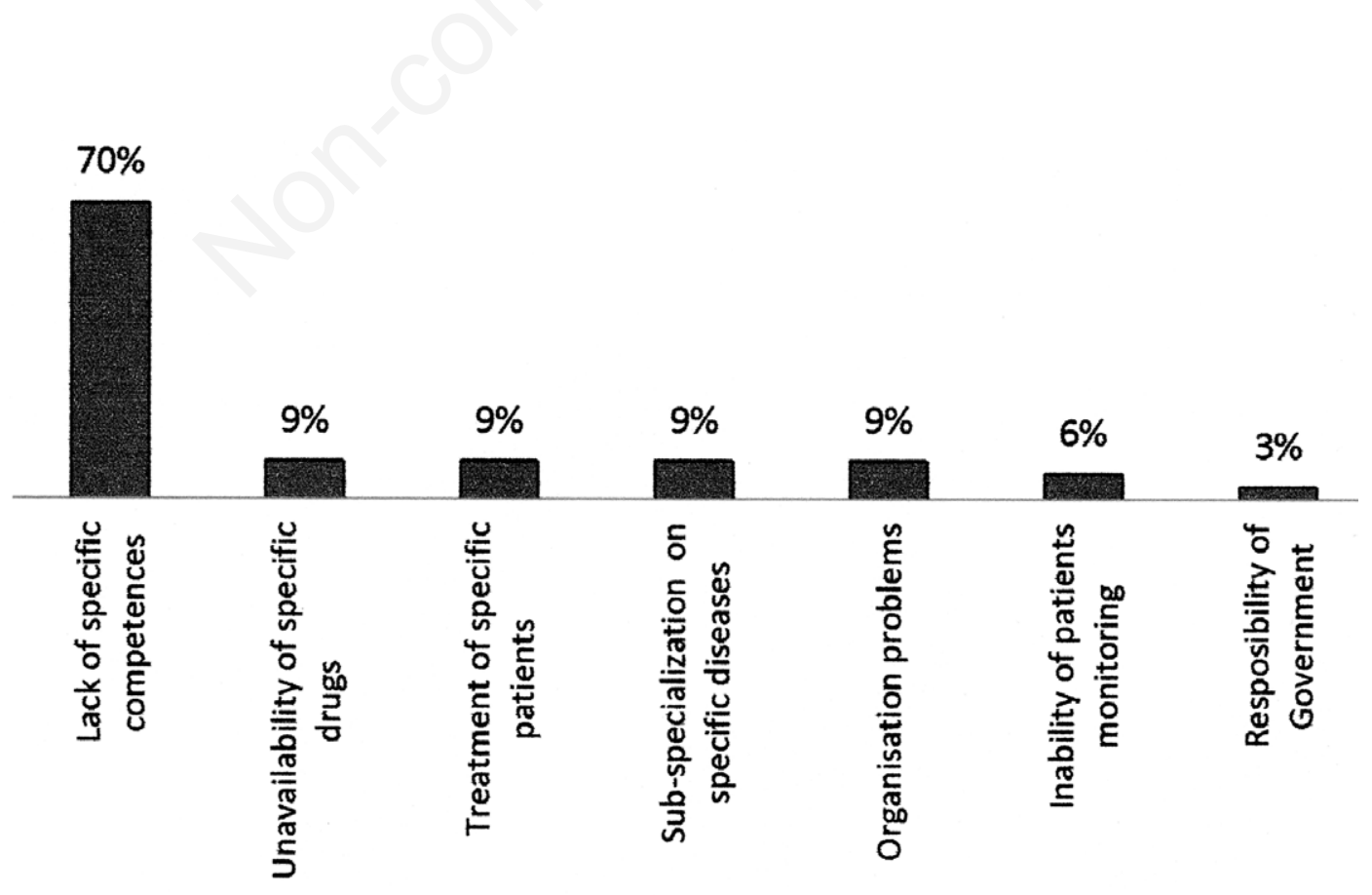

Figure 3. Reasons for lack of treatment of specific conditions by dispensing centers. Data are expressed as percentages. 
tion levels have been linked to protective effects against overall and cardiovascular mortality. ${ }^{29}$

We also have to include in our analysis the issue that almost two out of three dispensing centres did not have the competence to meet the requests of some categories of patients (e.g., psychiatric, oncologic, type I diabetic, urologic and gynecologic). This becomes especially relevant if we consider that the incidence of psychiatric diseases is gradually increasing in Western Countries $^{30}$ and that these disorders are known to be overall more prevalent in migrants. ${ }^{31-33}$ The low use of psycho-active drugs in our population could therefore reflect the limited competence of our centers rather than a low prevalence of these illnesses in our population. The same considerations can apply to other ATC groups such as drugs for blood and hematopoietic organs, antineoplastic and immunomodulators and insulins, which are among the most widely dispensed drugs within the $\mathrm{SSN},{ }^{8}$ but are scarcely or not at all dispensed by the centers supplied by BF. This issue needs to be addressed in the future since prescription and adherence to these treatments have a great geographical variability as recently demonstrated e.g., for atrial fibrillation. ${ }^{34}$

Finally, it is worth noting that the vast majority of patients sought medical assistance spontaneously at our centers. This is generally reliant on the perception of the illness that patients hold and the different weight that is attributed to the sick role, determining its priority and degree of urgency. As the threshold for presentation to healthcare services can be higher in those from lower socio-economic backgrounds ${ }^{35}$ this can constitute an additional epidemiological bias and presumably lead to an underestimate of the prevalence of certain disorders within our analysed community.

\section{Conclusions}

To our knowledge, this is a first attempt to characterise and study a vulnerable population served by charitable medical services - particularly on Italian territory. A significant disparity has been highlighted by our work in the diseases encountered in people cared for by the charities supplied by the BF compared to patients within the Italian SSN. The greater prevalence of respiratory and gastrointestinal pathologies in our vulnerable study population may reflect its lower socio-economic status but also a number of epidemiological biases, including different perceptions of the sick role in a heavily low income community with a wide variety of cultural backgrounds. It is therefore hard to discriminate whether these differences are due to different susceptibility to specific diseases or different health needs. Moreover, further differences could emerge if it could be possible to group the patients according to their origin. This was not possible in our work and does not appear to be possible in the near future due to the peculiarities of this population as mentioned above. However, it is clear that our charitable services need to target a different population profile than the Italian SSN. Being aware of these differences could be useful for clinicians when dealing with these patients in emergency or medicine departments.

In spite of its already mentioned limitations, this study represents a preliminary attempt to evaluate the health needs of a vulnerable population, such are the users of the charities supplied by the BF. Overall, our work confirms that data concerning drug use and prescription can be the basis for specific health interventions and are likely to represent the only source to assess and monitor health needs in such patients.

\section{References}

1. Murray CJL, Lopez AD. Measuring the Global burden of Diseases. N Engl J Med 2013;369:448-57.

2. Prabhat J. Counting the dead is one of the world's best investments to reduce premature mortality. Hypothesis 2012;10:e3.

3. Moussa MA, Shafie MZ, Kogali MM, et al. Reliability of death certificate diagnoses. J Clin Epidemiol 1990;43: 1285-95.

4. Lasser KE, Himmelstein DU, Woolhandler S. Access to care, health status, and health disparities in the United States and Canada: results of a cross-national population-based survey. Am J Public Health 2006;96:300-7.

5. Ministero Italiano della Salute. Gli strumenti: il metodo di classificazione ATC/DDD. Bollettino di Informazione sui Farmaci n. 6. Roma: Ministero Italiano della Salute; 2003, pp 59-62.

6. WHO Collaborating Centre for Drug Statistics Methodology. Guidelines for ATC classification and DDD assignment 2013. Oslo: Norwegian Institute of Public Health; 2013. Available from: http://www.whocc.no/filearchive/ publications/1_2013guidelines.pdf

7. Osservatorio Donazione Farmaci. Donare per curare Povertà sanitaria e donazione farmaci - Rapporto 2015. Milano: Banco Farmaceutico Fondazione ONLUS; 2015. Available from: http://www.bancofarmaceutico.org/detail.asp? $=1 \& p=0 \& \mathrm{id}=729$

8. Osservatorio Nazionale sull'impiego dei Medicinali. L'uso dei farmaci in Italia. Rapporto Nazionale Gennaio-Settembre 2013. Roma: Agenzia Italiana del Farmaco; 2014.

9. Rogot E, Sorlie PD, Johnson NJ, et al. A mortality study of 1.3 million persons by demographic, social and economic factors: 1979-1985 follow-up: US National Longitudinal Mortality Study. NIH publication No 92-3297. Bethesda: National Institutes of Health; 1992.

10. Menezes AMB, Victora CG, Rigatto M. Prevalence and risk factors for chronic bronchitis in Pelotas, Brazil: a population-based study. Thorax 1994;49:1217-21.

11. Strachan DP. Epidemiology: a British perspective. In: Calverley P, Pride N, eds. Chronic obstructive pulmonary disease. London: Chapman \& Hall; 1995. pp 47-68.

12. Bakke PS, Hanoa R, Gulsvik A. Educational level and 
obstructive lung disease given smoking habits and occupational airborne exposure: a Norwegian community study. Am J Epidemiol 1995;141:1080-8.

13. Prescott E, Lange P, Vestbo J. Socioeconomic status, lung function and admission to hospital for COPD: results from the Copenhagen City Heart Study. J Eur Respir 1999;13:1109-14.

14. Hunter DJ, Reddy KS. Noncommunicable diseases. N Engl J Med 2013;369:1336-43.

15. Tockman MS, Khoury MJ, Cohen BH. The epidemiology of COPD. In: Petty TL, ed. Chronic obstructive pulmonary disease. New York, NY: Marcel Dekker; 1985. pp 78-9.

16. Strachan DP, Cox BD, Erzinclioglu SW, et al. Ventilatory function and winter fresh fruit consumption in a random sample of British adults. Thorax 1991;46:624-29.

17. Chapman KM, Winter L. COPD: using nutrition to prevent respiratory function decline. Geriatrics 1996;51: 37-42.

18. Hegewald MJ, Crapo RO. Socioeconomic status and lung function. Chest 2007;132:1608-14.

19. Ezzati M, Riboli E. Behavioral and dietary risk factors for noncommunicable diseases. N Engl J Med 2013;369: 954-64.

20. Rundo B, Leoni M, Pizzo D, et al. Bambini immigrati in pronto soccorso: studio epidemiologico. Boll Soc Med Chir Pavia 2009;122:231-40.

21. Britten N, Daves JMC, Colley JRT. Early respiratory experience and subsequent cough and peak expiratory flow rate in 36-year-old men and women. BMJ 1987;294: 1317-20.

22. Andretta M, Cinconze E, Costa E, et al. Farmaci e immigrati. Rapporto sulla prescrizione farmaceutica in un paese multietnico. Roma: Il Pensiero Scientifico Editore; 2013.

23. Pace F, Vigneri S. Helicobacter Pylori. Milano: SpringerVerlag Italia; 1999.
24. Beer-Borst S. Obesity and other health determinants across Europe: the EURALIM Project. J Epidemiol Commun Health 2000;54:424-30.

25. Lindstrom M, Hanson BS, Ostergren PO. Socioeconomic differences in leisure-time physical activity: the role of social participation and social capital in shaping health related behaviour. Soc Sci Med 2001;52:441-51.

26. Broms U, Silventoinen K, Lahelma E, et al. Smoking cessation by socioeconomic status and marital status: the contribution of smoking behavior and family background. Nicotine Tob Res 2004;6:447-55.

27. Stringhini S, Sabia S, Shipley M, et al. Association of socioeconomic position with health behaviors and mortality. JAMA 2010;24:1159-66.

28. Marın-Guerrero AC, Gutierrez-Fisac JL, Guallar-Castillon $\mathrm{P}$, et al. Prevalencia de obesidad en inmigrantes en Madrid. Med Clin (Barc) 2010;134:483-85.

29. Mackenbach JP. Widening socioeconomic inequalities in mortality in six Western European Countries. Int J Epidemiol 2003;32:830-7.

30. Schumann G, Binder EB, Holte A. Stratified medicine for mental disorders. Eur Neuropsychopharmacol 2014; 24:5-50.

31. Bhugra D, Jones P. Migration and mental illness. Adv Psychiatr Treat 2001;7:216-23.

32. Bhugra D. Migration, distress and cultural identity. $\mathrm{Br}$ Med Bull 2004;69:129-41.

33. Selten JP, Cantor Graae E, Kahn R. Migration and schizophrenia. Curr Opin Psychiatr 2007;20:111-5.

34. Raparelli V, Proietti M, Buttà C, et al. Medication prescription and adherence disparities in non valvular atrial fibrillation partients: an Italian portrait from the ARAPACIS study. Intern Emerg Med 2014;9:861-70.

35. Cott CA, Gignac MA, Badley EM. Determinants of selfrated health for Canadians with chronic disease and disability. J Epidemiol Commun Health 1999;53:731-36. 